\title{
Radiation correction and uncertainty evaluation of RS41 temperature sensors by using an upper-air simulator
}

\author{
Sang-Wook Lee ${ }^{1,2}$, Sunghun Kim ${ }^{1}$, Young-Suk Lee ${ }^{1}$, Byung Il Choi ${ }^{1}$, Woong Kang ${ }^{1}$, Youn Kyun Oh${ }^{1}$, \\ Seongchong Park ${ }^{1}$, Jae-Keun Yoo ${ }^{1}$, Joohyun Lee ${ }^{3}$, Sungjun Lee ${ }^{1}$, Suyong Kwon ${ }^{1,2}$, and Yong-Gyoo Kim ${ }^{1}$ \\ ${ }^{1}$ Division of Physical Metrology, Korea Research Institute of Standards and Science, Daejeon 34113, Republic of Korea \\ ${ }^{2}$ Department of Science of Measurement, University of Science and Technology, Daejeon 34113, Republic of Korea \\ ${ }^{3}$ Frontier of Extreme Physics, Korea Research Institute of Standards and Science, Daejeon 34113, Republic of Korea
}

Correspondence: Yong-Gyoo Kim (dragon@kriss.re.kr)

Received: 11 August 2021 - Discussion started: 28 September 2021

Revised: 19 January 2022 - Accepted: 25 January 2022 - Published: 4 March 2022

\begin{abstract}
An upper-air simulator (UAS) has been developed at the Korea Research Institute of Standards and Science (KRISS) to study the effects of solar irradiation of commercial radiosondes. In this study, the uncertainty in the radiation correction of a Vaisala RS41 temperature sensor is evaluated using the UAS at KRISS. First, the effects of environmental parameters including the temperature $(T)$, pressure $(P)$, ventilation speed $(v)$, and irradiance $(S)$ are formulated in the context of the radiation correction. The considered ranges of $T, P$, and $v$ are -67 to $20^{\circ} \mathrm{C}, 5-500 \mathrm{hPa}$, and $4-7 \mathrm{~m} \mathrm{~s}^{-1}$, respectively, with a fixed $S_{0}=980 \mathrm{~W} \mathrm{~m}^{-2}$. Second, the uncertainties in the environmental parameters determined using the UAS are evaluated to calculate their contribution to the uncertainty in the radiation correction. In addition, the effects of rotation and tilting of the sensor boom with respect to the irradiation direction are investigated. The uncertainty in the radiation correction is obtained by combining the contributions of all uncertainty factors. The expanded uncertainty associated with the radiation-corrected temperature of the RS41 is $0.17^{\circ} \mathrm{C}$ at the coverage factor $k=2$ (approximately $95 \%$ confidence level). The findings obtained by reproducing the environment of the upper air by using the ground-based facility can provide a basis to increase the measurement accuracy of radiosondes within the framework of traceability to the International System of Units.
\end{abstract}

\section{Introduction}

The measurement of temperature and humidity in the free atmosphere is of significance for weather prediction, climate monitoring, and aviation safety assurance. Radiosondes are telemetry devices that include various sensors to perform in situ measurements and transmit the measured data to a ground receiver while the device is carried by a weather balloon to an altitude of approximately $35 \mathrm{~km}$. Since their development in the 1930s, radiosondes have been widely used to measure various essential climate variables (ECVs) such as the temperature, water vapour, pressure, wind speed, and wind direction in the upper-air atmosphere. Owing to their high accuracy of 0.3 to $0.4 \mathrm{~K}$ claimed by manufacturers (Vaisala), radiosonde measurements provide a reference for other remote sensing techniques such as those based on satellite and lidar. However, evaluation methods for their sensor accuracy are not fully disclosed to users. Operation principles of laboratory set-ups, algorithms to correct measurement errors, and corresponding uncertainty evaluations are prerequisites for a reference data product. The dependence of accuracy evaluation based only on manufacturer data may lead to inhomogeneities in data records due to the use of different radiosonde models.

To ensure the quality control of measurements in the upper air, the Global Climate Observing System (GCOS) Reference Upper-Air Network (GRUAN) was founded in 2008. The key objective of the GRUAN is to perform high-quality measurements of selected ECVs from the surface to the stratosphere to monitor climate change. To this end, the required temperature measurement accuracy in the troposphere and stratosphere has been specified as 0.1 and $0.2 \mathrm{~K}$, respectively (GCOS, 2007). 
The main source of error in the temperature measured by radiosondes is solar radiation during sounding in daytime. The temperature sensors of most commercial radiosondes are exposed to solar radiation, which leads to radiative heating of the temperature sensor. According to the last intercomparison of high-quality radiosonde systems (Nash et al., 2011), radiation correction values applied by manufacturers were distributed from 0.6 to $2.3 \mathrm{~K}$ at $10 \mathrm{hPa}$. More recently, according to the radiation correction of the Vaisala RS41 (Vaisala, 2022), it is increased from 0.53 to $1.16 \mathrm{~K}$ at $10 \mathrm{hPa}$ as the solar angle is elevated from 0 to $90^{\circ}$. Correcting the radiation effect is challenging because the temperature of sensors is also affected by other thermal exchange processes such as conduction from the sensor boom, convective cooling by air ventilation, and long-wave radiation from sensors. To minimize the effect of radiative heating of radiosonde temperature sensors, the size of the sensors has been reduced (de Podesta et al., 2018), and highly reflective coatings are used (Luers and Eskridge, 1995; Schmidlin et al., 1986). Moreover, the sensor boom has been redesigned to reduce the thermal conduction to sensors. Nevertheless, the effect of solar irradiation cannot be eliminated and thus should be corrected properly.

Many researchers have attempted to correct the radiation effect on radiosonde temperature sensors through theoretical and experimental techniques. The early theoretical approaches were based on heat transfer equations governing the thermal exchange between the sensor and surrounding media (Luers, 1990; McMillin et al., 1992). However, the application of these approaches requires complete knowledge regarding the material properties of the sensor and sensor boom and air characteristics in a wide range of temperatures, and the aerodynamic characteristics for a specific sensor geometry must be determined.

A few researchers performed in-flight experiments to derive a formula to correct the radiation effect. Radiation correction was estimated by using radiosondes equipped with four thermistors having coatings with different spectral responses, i.e. emissivities and absorptivities (Schmidlin et al., 1986). A correction formula was derived by establishing the relationship between the irradiance and increase in the temperature via radiative heating during daytime sounding (Philipona et al., 2013). Two identical thermocouples were used to measure the temperature difference when only one sensor was exposed to solar radiation, and the other was shielded. As a result, radiation correction was obtained by a linear function of geopotential height, which gives $1 \mathrm{~K}$ at $32 \mathrm{~km}$. However, the effect of the shield could not be eliminated.

Other groups adopted a chamber system for radiation correction by simulating the upper-air environments including the solar radiation. The GRUAN conducted experiments by using a chamber that could imitate the pressure, air ventilation, and solar irradiance by using a vacuum pump, fan, and lamp or sunlight, respectively (Dirksen et al., 2014).
Recently, the same group conducted experiments by using a new laboratory set-up including a wind tunnel with various functionalities and improved uncertainties in processing the GRUAN data for the Vaisala RS41 sensors (von Rohden et al., 2022). However, these experiments were conducted at room temperature, and thus, the influence of the ambient temperature on the radiation error was not investigated. Notably, a previous study based on a chamber system reported that the solar-irradiation-induced temperature rise of sensors increases as the air temperature is decreased (Lee et al., 2018a).

Recently, the Korea Research Institute of Standards and Science (KRISS) developed an upper-air simulator (UAS) that can simultaneously control the temperature, pressure, air ventilation, and irradiation (Lee et al., 2020). This UAS has been also used to calibrate the relative humidity sensors of commercial radiosondes at low temperatures (down to $-67^{\circ} \mathrm{C}$ ) (Lee et al., 2021).

In this study, the uncertainty in the radiation correction of a Vaisala RS41 temperature sensor is evaluated using the UAS developed at KRISS (Lee et al., 2020). It is shown how the uncertainty in each environmental parameter and radiosonde movements in the UAS contributes to the uncertainty of the RS41 through a radiation correction formula obtained by a series of radiation experiments. The layout of the UAS is described in Sect. 2, along with the addition of new functions to consider the effect of the rotation and tilting of the sensor, which are important improvements from the previous version of the UAS. As described in Sect. 3, a radiation correction formula for the RS41 sensor is derived through a series of experiments involving varying temperature $(T)$, pressure $(P)$, and ventilation speed $(v)$ values in the following ranges: -67 to $20^{\circ} \mathrm{C}, 5-500 \mathrm{hPa}$, and $4-7 \mathrm{~m} \mathrm{~s}^{-1}$, respectively, with a fixed irradiance $S_{0}=980 \mathrm{~W} \mathrm{~m}^{-2}$. The effects of sensor rotation and tilting with respect to the incident irradiation are also investigated. Section 4 describes the evaluation of the uncertainties associated with the environmental parameters and sensor motions and positions controlled in the UAS to calculate the contribution of these factors to the uncertainty in the radiation correction. This study can help enhance the measurement accuracy of radiosondes within the framework of traceability to the International System of Units (SI) by providing a methodology for radiation correction in an environment similar to that which may be encountered by radiosondes.

\section{Layout of the UAS}

\subsection{Temperature control of the radiosonde test chamber by using a climate chamber}

Figure 1a shows the test chamber of the UAS with an installed radiosonde for the radiation correction. The test chamber is inside a climate chamber (Tenney Environmen- 
tal, Model C64RC) with a $1219 \mathrm{~mm} \times 1219 \mathrm{~mm} \times 1219 \mathrm{~mm}$ working space. The temperature of the test chamber is controlled by the climate chamber. Air is precooled before entering into the climate chamber by passing through a heat exchanger in a separate bath (Kambič Metrology, Model OB$50 / 2$ ULT) with a temperature lower than that of the climate chamber by about $5^{\circ} \mathrm{C}$. The temperature of the precooled air is then adjusted to that of the climate chamber while passing through the second heat exchanger ( $9.3 \mathrm{~m}$ in length) in the climate chamber before entering into the test chamber. The radiosonde is installed upside down, as shown in Fig. 1b, and the air flows into the test chamber from the bottom. The temperature of the test chamber is measured using a calibrated platinum resistance thermometer (PRT).

\subsection{Pressure and ventilation speed control through sonic nozzles and a vacuum pump}

To control the air ventilation speed at low pressures, sonic nozzles, also known as critical flow Venturi, are used. The sonic nozzles are fabricated as toroidal-throat Venturi nozzles to comply with the ISO 9300 standard (ISO, 2005) and calibrated using a low-pressure gas flow standard system at KRISS (Choi et al., 2010). Thus, the reference value and SI traceability of the ventilation speed are obtained by using the sonic nozzles in the UAS. Sonic nozzles can be used to achieve a specific maximum constant flow when the ratio of the downstream pressure $\left(P_{\mathrm{e}}\right)$ to the upstream pressure $\left(P_{\mathrm{o}}\right)$ is smaller than a certain critical point $\left(P_{\mathrm{e}} / P_{\mathrm{o}}<P_{\mathrm{c}} / P_{\mathrm{o}}\right)$. The test chamber lies in the downstream region of the sonic nozzles, in which the pressure is lowered using a vacuum pump (WONVAC, Model WOVP-0600) to attain the critical condition. Six sonic nozzles with different throat diameters are used to generate air ventilation speeds ranging from 4 to $7 \mathrm{~m} \mathrm{~s}^{-1}$ in the pressure range of $5-500 \mathrm{hPa}$. The generated airflow is measured through laser Doppler velocimetry (LDV) (Dantec, Model BSA F60) to investigate the spatial gradient in the test chamber. An Ar ion laser $(3 \mathrm{~W})$ with a wavelength of $514.5 \mathrm{~nm}$ is used for the LDV with a focal length of $400.1 \mathrm{~mm}$ and nominal beam spacing of $33 \mathrm{~mm}$.

\subsection{Irradiation control by using a solar simulator}

Solar irradiation is imitated by using a solar simulator with a xenon DC arc lamp (Newport, Model 66926-1000XF-R07). The virtual sunlight is irradiated onto the radiosonde temperature sensor and the sensor boom through quartz windows of the test chamber. A constant irradiance of $980 \mathrm{~W} \mathrm{~m}^{-2}$ at the position of the radiosonde sensors inside the test chamber is adopted throughout this study. The two-dimensional distribution of the irradiance is recorded at the radiosonde sensor location by using a calibrated Si photodiode (Thorlabs, Model SM05PD2A). The spatial uniformity of the irradiance around the sensor position is within $\pm 5 \%$. In addition, the irradiance is monitored to check its drift during the exper- iments by using a photodiode-based pyranometer (Apogee, Model SP-110-SS) installed behind the test chamber. The pyranometer is calibrated at KRISS, and the uncertainty is $1 \%$ of the measured value with a coverage factor $k=1$.

\subsection{Installation of the RS41}

The uncertainty associated with the radiation correction for a commercial radiosonde (Vaisala, RS41) is evaluated using the UAS. A complete RS41 unit including the sensor boom, antenna, and main body is installed upside down in the test chamber, as shown in Fig. 1a and b. The sensor boom is placed parallel to the airflow (dashed blue arrows). The sensor boom is irradiated (dotted red arrows) by the solar simulator in a perpendicular manner through quartz windows $(50 \mathrm{~mm} \times 70 \mathrm{~mm})$. The temperature recorded by the RS41 is collected through remote data transmission as in the case of soundings by the Vaisala sounding system MW41. Radiation correction by the manufacturer is applied only during the sounding state. The RS41 unit remains at the pre-sounding state in the manual sounding mode throughout the data acquisition, and thus, raw temperature with no radiation correction is obtained.

\subsection{Rotation and tilting of the sensor boom}

A radiosonde exhibits continuous movements such as pendulum and rotational motions during sounding. The geometry of the temperature sensor of the Vaisala RS41 is a rod shape, and thus the rotation and tilt affect the effective irradiance and the direction of air ventilation. Other radiosondes using spherical bead thermistors would be less affected by the rotation and tilt. Thus, the angle of the sensor boom with respect to the radiation direction or airflow may constantly vary. To consider this aspect, the UAS is modified to be able to simulate these situations through rotating and tilting of the sensor boom in the test chamber. Figure 1c-e illustrate the mechanisms in the test chamber that enable the (Fig. 1d) rotation of the radiosonde around the vertical axis and (Fig. 1e) tilting of the sensor boom from the (Fig. 1c) normal position. The rotation cycle and tilt are controlled using stepper motors. Rotation cycles of 5, 10, and $15 \mathrm{~s}$ are employed. The maximum tilt is $27^{\circ}$ with respect to the vertical axis. Effects of the rotation and incident angle of irradiation are studied and incorporated into the uncertainty evaluation of the radiation correction of the sensor.

\section{Experiment details}

\subsection{Effect of pressure}

Radiation error is the temperature difference between the sensor with irradiation and air $\left(T_{\text {on }}-T_{\text {air }}\right)$. However, the air temperature measured in the current chamber system does not represent that in the free atmosphere since the air is 

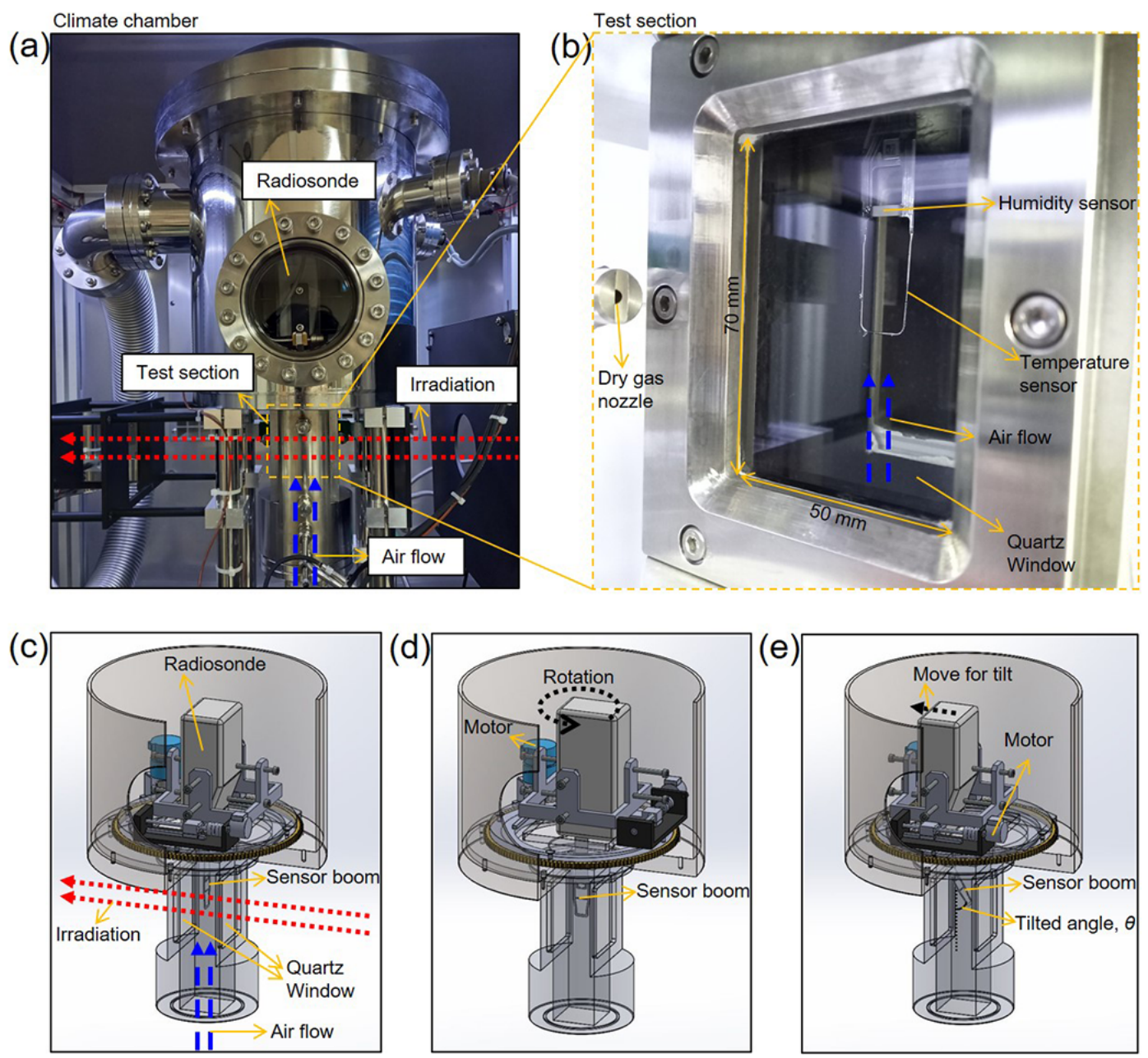

Figure 1. Photographs of the (a) upper-air simulator (UAS) and (b) test section with a radiosonde (Vaisala, RS41). Schematics of the radiosonde in the UAS in (a) normal, (b) rotating, and (c) tilted positions.

heated by irradiation for a short time while passing through the test section. It is difficult to measure true air temperature in a shaded area in the test chamber using an independent thermometer because the test section is also slightly heated by the irradiation. The temperature measured below the window is continuously increased by a few tens of millikelvins while repeating the experiments for $10 \mathrm{~min}$. Thus, the radiation correction value $\left(\Delta T_{\mathrm{rad}}\right)$ is obtained by the difference in the temperatures with irradiation $\left(T_{\mathrm{on}}\right)$ and without irradiation $\left(T_{\text {off }}\right)$ as previously reported (Lee et al., 2020): $\Delta T_{\text {rad }}=T_{\text {on }}-T_{\text {off. }}$. The duration of irradiation is $120 \mathrm{~s}$, and the measurement is repeated three times.

It has been reported that $\Delta T_{\text {rad }}$ significantly increases as the pressure $(P)$ decreases from 100 to $7 \mathrm{hPa}$ in the UAS (Lee et al., 2020). In this study, the pressure range is extended $(5-500 \mathrm{hPa})$ to formulate the corresponding effect at a more practical scale. Figure 2a shows $\Delta T_{\text {rad }}$ as a function of pressure from 5 to $500 \mathrm{hPa}$ with varying temperature $(T)$ from -67 to $20^{\circ} \mathrm{C}$. The data represent the mean and the standard deviation of three repeated measurements on a single RS41 unit. The biggest standard deviation was $0.014{ }^{\circ} \mathrm{C}$. The enhanced increase in $\Delta T_{\text {rad }}$ is observed at low pressures for all measured temperatures because the convective cooling process is weakened as the air density decreases at low pressures. The effect of temperature is well distinguished in the low-pressure range ( 5 to $50 \mathrm{hPa}$ ), whereas it is not clearly observable in the high-pressure range $(100$ to $500 \mathrm{hPa})$. This phenomenon can be attributed to the fact that the uncertainty in $\Delta T_{\text {rad }}$ becomes relatively larger with respect to $\Delta T_{\text {rad }}$ as $\Delta T_{\text {rad }}$ is decreased at high pressures in the UAS.

To parameterize a radiation correction formula in terms of $T$ and $P, \Delta T_{\text {rad }}$ at each temperature is fitted individually by using an empirical polynomial function of $\log _{10} P$, as indicated by dashed lines in Fig. 2a. The fitting equations represented in Fig. 2a are as follows:

$$
\begin{gathered}
\Delta T_{\mathrm{rad}}=A_{0}(T)+B_{0}(T) \cdot \log (P)+C_{0}(T) \cdot[\log (P)]^{2} \\
\text { for } 5 \mathrm{hPa} \leq P \leq 500 \mathrm{hPa}, \quad S_{0}=980 \mathrm{~W} \mathrm{~m}^{-2},
\end{gathered}
$$



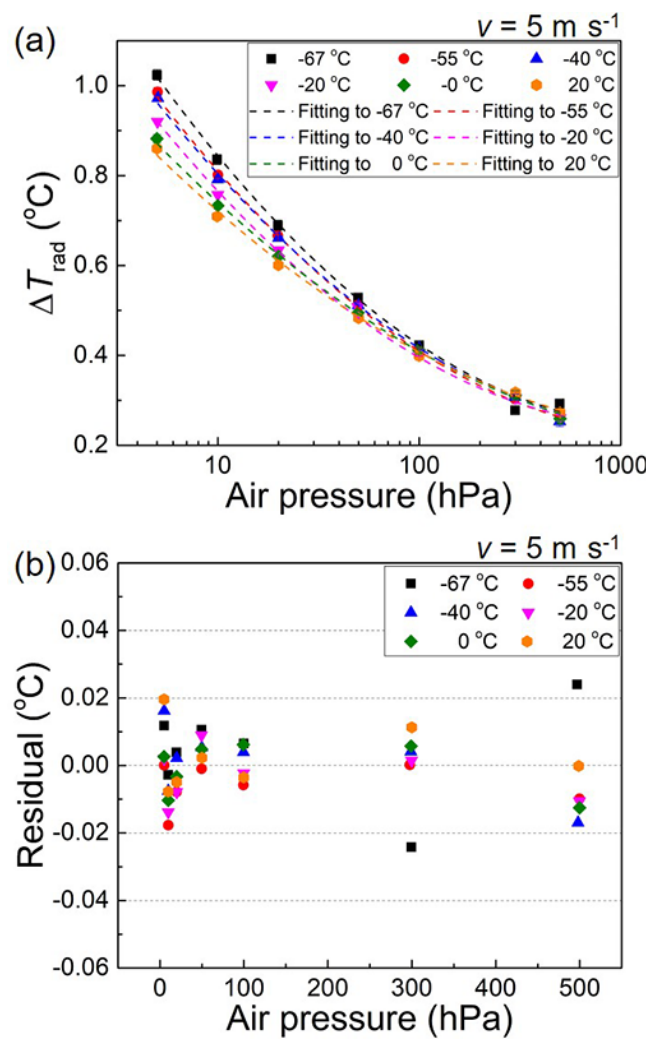

Figure 2. Temperature rise $\left(T_{\mathrm{rad}}\right)$ in a RS41 temperature sensor due to irradiation as a function of the air pressure in the range of (a) 5$500 \mathrm{hPa}$ and (b) residuals as a function of air pressure when Eq. (1) is used.

where $A_{0}(T), B_{0}(T)$, and $C_{0}(T)$ are fitting coefficients with functions of $T$, having units of ${ }^{\circ} \mathrm{C},{ }^{\circ} \mathrm{C} \cdot[\log \mathrm{hPa}]^{-1}$, and ${ }^{\circ} \mathrm{C} \cdot[\log \mathrm{hPa}]^{-2}$, respectively. The irradiation intensity $S_{0}$ is set as $980 \mathrm{~W} \mathrm{~m}^{-2}$ throughout this study.

\subsection{Effect of temperature}

The following $T$ values are used in the test chamber: -67 , $-55,-40,-20,0$, and $20^{\circ} \mathrm{C}$. As shown in Fig. $2 \mathrm{a}, \Delta T_{\text {rad }}$ gradually increases as the temperature reduces, especially in the low-pressure range of 5-50 hPa. To incorporate the temperature effect in Eq. (1), the coefficients are fitted with empirical linear functions as follows:

$A_{0}(T)=a_{0} \cdot T+a_{1}$,

$B_{0}(T)=b_{0} \cdot T+b_{1}$

$C_{0}(T)=c_{0} \cdot T+c_{1}$,

where $a_{0}, a_{1}, b_{0}, b_{1}, c_{0}$, and $c_{1}$ are fitting coefficients. Information regarding these coefficients is summarized in Table 1.

The residuals obtained using Eq. (1) and the associated fitting coefficients listed in Table 1 are presented in Fig. $2 b$. The fitted values agree with the measurement data within $\pm 0.03^{\circ} \mathrm{C}$.
Table 1. Coefficients in Eqs. (2), (3), and (4).

\begin{tabular}{llr}
\hline Coefficient & Unit & Value \\
\hline$a_{0}$ & & $-3.69 \times 10^{-3}$ \\
$a_{1}$ & ${ }^{\circ} \mathrm{C}$ & 1.25 \\
$b_{0}$ & {$[\operatorname{log~hPa}]^{-1}$} & $2.84 \times 10^{-3}$ \\
$b_{1}$ & ${ }^{\circ} \mathrm{C} \cdot[\operatorname{loghPa}]^{-1}$ & $-5.98 \times 10^{-1}$ \\
$c_{0}$ & {$[\operatorname{log~hPa}]^{-2}$} & $-5.38 \times 10^{-4}$ \\
$c_{1}$ & ${ }^{\circ} \mathrm{C} \cdot[\operatorname{loghPa}]^{-2}$ & $8.66 \times 10^{-2}$ \\
\hline
\end{tabular}

In order to understand the observed temperature effect theoretically, the temperature sensor is modelled as a sphere made of platinum $(\mathrm{Pt})$ with a diameter $(D)$ of $1 \mathrm{~mm}$. The $\mathrm{Pt}$ sphere is placed in the middle of an airflow $(v)$ with varied temperature $\left(T_{\mathrm{a}}\right)$ and pressure $\left(P_{\mathrm{a}}\right)$, as shown in Fig. 3a. The sphere is heated by the absorption of the solar irradiance $\left(S=1000 \mathrm{~W} \mathrm{~m}^{-2}\right)$ and cooled by the forced air convection $\left(5 \mathrm{~m} \mathrm{~s}^{-1}\right)$, similar to the experiment. The radial and angular temperature distribution of the sphere is neglected and assumed to be uniform. Then, the steady-state temperature of the sphere $\left(T_{\mathrm{S}}\right)$ is simply decided by the energy balance of the heat transfer exchange as follows:

$\alpha S=h\left(T_{\mathrm{s}}-T_{\mathrm{a}}\right)$

with

$h=\frac{k}{D}\left[2+\left(0.4 \operatorname{Re}^{\frac{1}{2}}+0.06 \operatorname{Re}^{\frac{2}{3}}\right)\left(\frac{\mu C_{p}}{k}\right)^{2 / 5}\right]$,

where $\alpha$ is the absorptivity of the metal sphere, $S$ is the solar irradiance, and $h$ is the heat transfer coefficient (Incropera and Dewitt, 2002; Luers and Eskridge, 1995). The net heat transfer by longwave radiation from the Pt sphere is not considered because it is negligible $\left(\sim 10^{-6} \mathrm{~W}\right)$ compared to that by the convective heat transfer in Eq. (5). The heat transfer coefficient $h$ is determined by several parameters concerning the diameter of the sphere $(D)$ and the properties of air, including thermal conductivity $(k)$; viscosity $(\mu)$; heat capacity $\left(C_{p}\right)$; and Reynolds number $\left(R e=\rho v D \mu^{-1}\right)$, where $\rho$ and $v$ are the density of air and wind speed, respectively.

The radiation correction $\left(T_{\mathrm{s}}-T_{\mathrm{a}}\right)$ at $T_{\mathrm{a}}=20$ and $-70^{\circ} \mathrm{C}$ is calculated by Eq. (5) and displayed together with the experimental values (mean and standard deviation of three repeated experiments) as shown in Fig. 3b. The properties of air $\left(\mathrm{N}_{2}\right)$ used for the calculation refer to the NIST Chemistry WebBook (Linstrom and Mallard, 2001). In general, the calculated radiation correction of the Pt sphere is elevated as the pressure decreases as in the case of the experiment. This is because the heat transfer coefficient is reduced by about $35 \%$ as the density of air is decreased with varying pressure from $P_{\mathrm{a}}=50$ to $5 \mathrm{hPa}$. Interestingly, the temperature effect on the calculated radiation correction is also observed to be similar to the experiment. The theoretical value is roughly 
Table 2. Parameters and their values in Eq. (5) and the calculation of radiation correction at 20 and $-70{ }^{\circ} \mathrm{C}$.

\begin{tabular}{llrr}
\hline Parameter & Symbol (unit) & $\begin{array}{r}\text { Value } \\
\left(T_{\mathrm{a}}=20^{\circ} \mathrm{C}\right)\end{array}$ & $\begin{array}{r}\text { Value } \\
\left(T_{\mathrm{a}}=-70^{\circ} \mathrm{C}\right)\end{array}$ \\
\hline Diameter & $D(\mathrm{~m})$ & 0.001 & 0.001 \\
Air pressure & $P_{\mathrm{a}(\mathrm{hPa})}$ & 5 & 5 \\
Wind speed & $v\left(\mathrm{~m} \mathrm{~s}^{-1}\right)$ & 5 & 5 \\
Viscosity & $\mu(\mathrm{Pa} \mathrm{s})$ & 0.00001754 & 0.00001307 \\
Density & $\rho\left(\mathrm{kg} \mathrm{m}^{-3}\right)$ & 0.0057466 & 0.0082925 \\
Thermal conductivity & $k\left(\mathrm{~W} \mathrm{~m}^{-1} \mathrm{~K}^{-1}\right)$ & 0.025367 & 0.018869 \\
Heat capacity & $C_{p}\left(\mathrm{~J} \mathrm{~kg}^{-1} \mathrm{~K}^{-1}\right)$ & 1039.6 & 1039.1 \\
Reynolds number & $R e$ & 1.64 & 3.17 \\
\hline Heat transfer coefficient & $h\left(\mathrm{~W} \mathrm{~m}^{-2} \mathrm{~K}^{-1}\right)$ & 63.97 & 51.67 \\
Solar irradiance & $S\left(\mathrm{~W} \mathrm{~m}^{-2}\right)$ & 1000 & 1000 \\
Absorptivity of metal & $\alpha$ & 0.2 & 0.2 \\
\hline Radiation correction & $T_{\mathrm{S}}-T_{\mathrm{a}}(\mathrm{K})$ & 0.78 & 0.97 \\
\hline
\end{tabular}

(a)
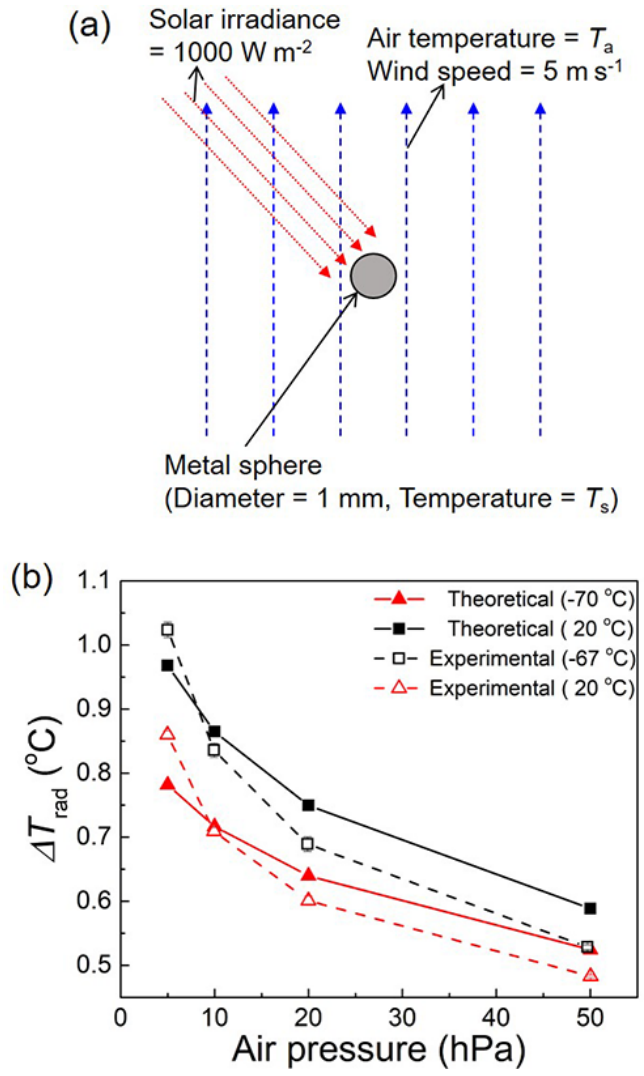

Figure 3. (a) Schematic diagram for calculation of radiation correction on a metal sphere and (b) $T_{\text {rad }}$ of the metal sphere obtained by the theoretical calculation using Eq. (5) and the experimental value by the UAS as a function of air pressure at two different temperatures. consistent with the experimental value within the uncertainty in $\Delta T_{\text {rad }}\left(0.1^{\circ} \mathrm{C}\right)$ as obtained in Sect. 4.9. A decrease in thermal conductivity of air by about $26 \%$ at $-70{ }^{\circ} \mathrm{C}$ is mainly responsible for the decrease in the heat transfer coefficient and thereby the increase in the radiation correction at low temperature $\left(-70^{\circ} \mathrm{C}\right)$. The thermal conductivity of air plays an important role for the heat transfer at the boundary between the air and the Pt sphere. The same phenomenon was also observed for thermistors even though there is no apparent air ventilation (Lee et al., 2018a), which may emphasize the role of thermal conductivity of air. The parameters and their values used for the calculation of radiation correction at $T_{\mathrm{a}}=20$ and $-70^{\circ} \mathrm{C}$ with $P_{\mathrm{a}}=5 \mathrm{hPa}$ are summarized in Table 2 .

It was previously observed that the temperature rise of the RS92 was initially fast due to the small thermal mass of the sensor and subsequently slow (Dirksen et al., 2014). More recently, the temperature of the RS41 oscillated when the radiosonde was rotating under irradiation (von Rohden et al., 2022). These observations are attributed to the fact that the heating of the sensor boom with a comparably large area is coupled to the heating of the temperature sensor. Since the conductive heat transfer from the sensor boom is missing in the above theoretical calculation, the comparison in Fig. $3 \mathrm{~b}$ may show the effect of the sensor boom on $\Delta T_{\text {rad }}$. Interestingly, the growth of $\Delta T_{\text {rad }}$ of the theoretical calculation is less steep than that of the experiment as the pressure is decreased to $5 \mathrm{hPa}$. This may imply that the heat transfer from the sensor boom becomes significant especially at low pressures.

\subsection{Estimation of the low-temperature effect}

The effect of low temperature on $\Delta T_{\text {rad }}$ is represented by the ratio (\%) of $\Delta T_{\text {rad }}$ to the corresponding value at $20^{\circ} \mathrm{C}$ $\left(\Delta T_{\text {rad_20 }}\right)$, as shown in Fig. 4a. The data represents the mean and the standard deviation of three repeated mea- 
(a)

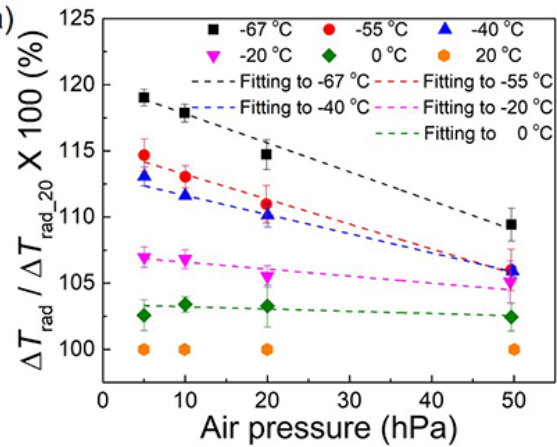

(b)

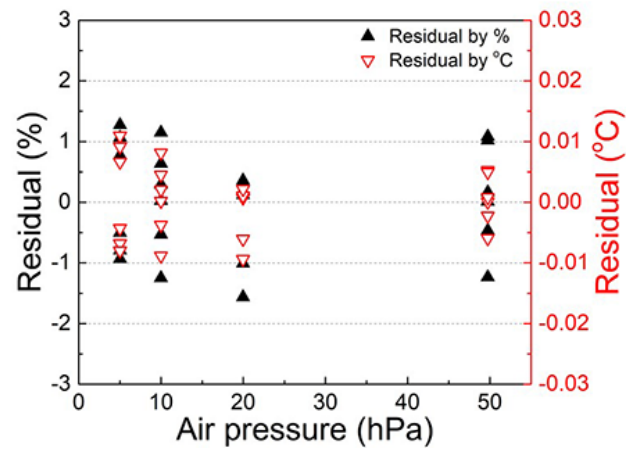

Figure 4. (a) Effect of temperature on $T_{\text {rad }}$ normalized by that at $20^{\circ} \mathrm{C}\left(T_{\text {rad } 20}=100 \%\right)$ and (b) residuals of linear fittings as a function of the air pressure.

surements on a single RS41 unit. The temperature effect $\left(\Delta T_{\text {rad }} / \Delta T_{\text {rad_20 }}\right)$ gradually increases as the temperature and pressure decrease. $\Delta T_{\text {rad }} / \Delta T_{\text {rad } \_20}$ is $119 \%$ at $T=-67^{\circ} \mathrm{C}$ and $P=5 \mathrm{hPa}$. To obtain the information required to estimate the low-temperature effect by using only $\Delta T_{\text {rad }}$ at $20^{\circ} \mathrm{C}$ with varied $P, \Delta T_{\text {rad }} / \Delta T_{\text {rad_20 }} \times 100$ is fitted with empirical linear functions:

$\Delta T_{\mathrm{rad}} / \Delta T_{\mathrm{rad} \_20} \times 100(\%)=D(T) \cdot P+E(T)$,

where $D(T)$, represented in $\mathrm{hPa}^{-1}$, and $E(T)$, which is dimensionless, are fitting coefficients with functions of $T$. $D(T)$ and $E(T)$ are fitted by linear functions of $T$ as follows:

$D(T)=d_{0} \cdot T+d_{1}$,

$E(T)=e_{0} \cdot T+e_{1}$,

where $d_{0}, d_{1}, e_{0}$, and $e_{1}$ are fitting coefficients. The information regarding these coefficients is summarized in Table 3.

The residuals obtained using Eqs. (6), (7), and (8) are represented in Fig. 4b. The estimated values agree with the measurement data within $\pm 1.5 \%$ (left $y$ axis), corresponding to approximately $\pm 0.01{ }^{\circ} \mathrm{C}$ (right $y$ axis). Using Eq. (6), the radiation correction for low temperatures can be estimated through only the room-temperature measurement. Since the temperature dependency is weak at higher pressures, there
Table 3. Coefficients in Eqs. (7) and (8).

\begin{tabular}{llr}
\hline Coefficient & Unit & Value \\
\hline$d_{0}$ & $\mathrm{hPa}^{-1}{ }^{\circ} \mathrm{C}^{-1}$ & $2.74 \times 10^{-3}$ \\
$d_{1}$ & $\mathrm{hPa}^{-1}$ & $-2.69 \times 10^{-2}$ \\
$e_{0}$ & ${ }^{\circ} \mathrm{C}^{-1}$ & $-0.23 \times 10^{0}$ \\
$e_{1}$ & & $1.04 \times 10^{2}$ \\
\hline
\end{tabular}

is no need to estimate the low-temperature effect at 50 $500 \mathrm{hPa}$, and the estimation using Eq. (6) is limited within $5-50 \mathrm{hPa}$.

\subsection{Effect of ventilation speed}

To investigate the effect of ascending speed of radiosondes, the air ventilation speed $(v)$ in the test chamber is systematically varied in the range of $4-7 \mathrm{~m} \mathrm{~s}^{-1}$. Figure 5a shows $\Delta T_{\text {rad }}$ as a function of the ventilation speed with the temperature varying from -67 to $20^{\circ} \mathrm{C}$. $\Delta T_{\text {rad }}$ decreases as the ventilation speed increases, primarily owing to the enhancement in the convective cooling. Because the pressure is fixed at $50 \mathrm{hPa}$, the temperature effect is clearly visible in Fig. $5 \mathrm{a}$. The measurement data at each temperature are fitted using a linear function (dashed lines) to formulate the effect of the ventilation speed. The slope of the linear functions indicates that an increase of $1 \mathrm{~m} \mathrm{~s}^{-1}$ in $v$ induces a decrease of $0.02-0.03{ }^{\circ} \mathrm{C}$ in $\Delta T_{\text {rad }}$. Figure $5 \mathrm{~b}$ shows $\Delta T_{\text {rad }}$ as a function of the ventilation speed with the pressure varying from 5 to $300 \mathrm{hPa}$. The measurement data at each pressure are fitted using a linear function (dashed lines). The slopes are distributed from -0.04 to $-0.02{ }^{\circ} \mathrm{C}\left(\mathrm{m} \mathrm{s}^{-1}\right)^{-1}$.

Although the effect of the ventilation speed is coupled with the temperature and pressure effects, the coupling represented by the variation in slopes in Fig. 5a and b is minor in the range of 4-7 $\mathrm{m} \mathrm{s}^{-1}$. Therefore, the effect of the ventilation speed can likely be treated as an independent parameter. Thus, the ventilation effect is formulated considering the av-

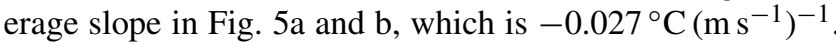
This result is incorporated into Eq. (1) at $v=5 \mathrm{~m} \mathrm{~s}^{-1}$ :

$$
\begin{aligned}
\Delta T_{\text {rad }} & =A_{0}(T)+B_{0}(T) \cdot \log (P)+C_{0}(T) \cdot[\log (P)]^{2} \\
& -0.027 \cdot(v-5) \\
& \text { for } 5 \mathrm{hPa} \leq P \leq 500 \mathrm{hPa}, \quad S_{0}=980 \mathrm{~W} \mathrm{~m}^{-2} .
\end{aligned}
$$

The residual obtained by applying Eq. (9) is shown in Fig. 5c. The fitted values agree with the measurement data within $\pm 0.04{ }^{\circ} \mathrm{C}$. The linear relationship between the ventilation speed and the radiation correction in Eq. (9) is only valid in the range of $4-7 \mathrm{~m} \mathrm{~s}^{-1}$. When $v$ is higher than $7 \mathrm{~m} \mathrm{~s}^{-1}$ or lower than $4 \mathrm{~m} \mathrm{~s}^{-1}$, the formula underestimates the correction value. 

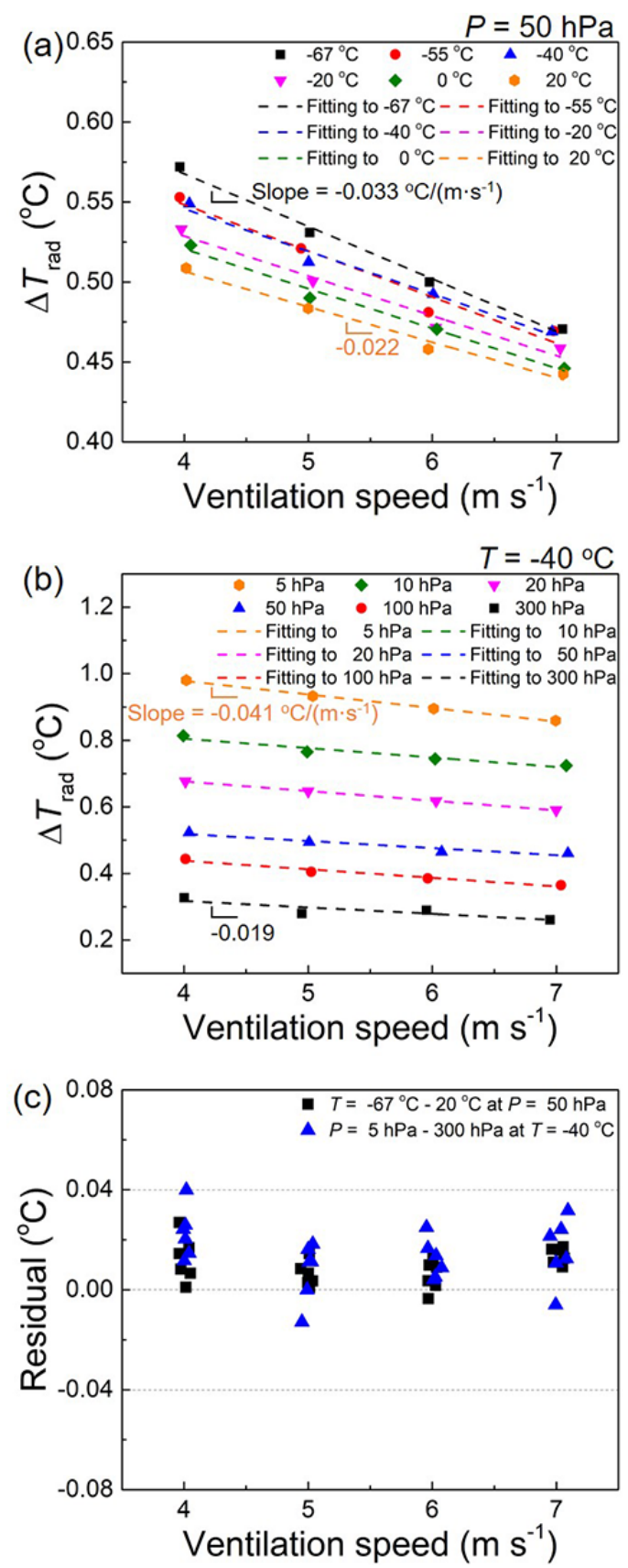

Figure 5. Effect of ventilation speed on $T_{\text {rad }}$ at (a) $P=50 \mathrm{hPa}$ at different temperatures and (b) $T=-40{ }^{\circ} \mathrm{C}$ at different air pressure values. (c) Residuals as a function of the ventilation speed when Eq. (9) is used.

\subsection{Effect of irradiation intensity}

The linear relationship between $\Delta T_{\text {rad }}$ and the irradiance $(S)$ is confirmed with reference to the existing studies based on theoretical and experimental approaches (Luers, 1990; McMillin et al., 1992; Lee et al., 2016). $S$ is independent of $T, P$, and $v$. As previously observed, the variation in the other parameters results in a change in only the slope of the linear functions ( $h$ in Eq. 5), and the linearity is not altered (Lee et al., 2018c, b). Because all the experiments performed in this study adopt a fixed $S_{0}=980 \mathrm{~W} \mathrm{~m}^{-2}$, and the empirical fitting coefficients are accordingly obtained, the effect of the irradiation intensity can be incorporated into Eq. (9) by using the linear relationship between $\Delta T_{\mathrm{rad}}$ and $S$ as follows:

$$
\begin{aligned}
\Delta T_{\text {rad }} & =S S_{0}^{-1} \times\left[A_{0}(T)+B_{0}(T) \cdot \log (P)\right. \\
& \left.+C_{0}(T) \cdot[\log (P)]^{2}-0.027 \cdot(v-5)\right] \\
& \text { for } 5 \mathrm{hPa} \leq P \leq 500 \mathrm{hPa}, \quad S_{0}=980 \mathrm{~W} \mathrm{~m}^{-2} .
\end{aligned}
$$

The radiation correction $\left(\Delta T_{\mathrm{rad}}\right)$ is then scaled with the actual irradiance $(S)$ by the factor of $S S_{0}^{-1}$. Consequently, Eq. (10) considers the radiation correction of the RS41 temperature sensor under simultaneously varying $T, P, v$, and $S$.

\subsection{Effect of sensor boom rotation}

The spinning motion of radiosondes during sounding is imitated by rotating the radiosonde in the test chamber, as shown in Fig. 1d. The rotation axis is the temperature sensor itself, not the centre of the boom in this work. Therefore, the temperature sensor only spins on the spot, and thus the distance between the sensor and the solar simulator does not change during the rotation. The amplitude of the temperature oscillation is investigated by varying the rotation cycle $(5,10$, and $15 \mathrm{~s})$ under irradiation, as shown in Fig. 6a. The maximum peak $\left(T_{\text {on_max }}\right)$ and minimum peak $\left(T_{\text {on_mim }}\right)$ appear alternately during the rotation. The difference between the peaks $\left(T_{\text {on_max }}-T_{\text {on_min }}\right)$ for $5 \mathrm{~s}$ duration is $0.01-0.02{ }^{\circ} \mathrm{C}$, which is around the measurement resolution of the $\operatorname{RS} 41\left(0.01^{\circ} \mathrm{C}\right)$, but is increased with the rotation period. Each peak appears twice in a single cycle, as clearly observed in the $15 \mathrm{~s}$ cycle. The exposed surface of the sensor boom depends on the incidence angle and passes through a maximum twice during a full rotation. The sensor boom experiences irradiation in the perpendicular and parallel directions at $T_{\mathrm{on} \_ \text {max }}$ and $T_{\mathrm{on} \_ \text {min }}$, respectively. This finding suggests that the conductive heat transfer from the boom to the sensor influences $T_{\text {on_max }}$.

Figure $6 \mathrm{~b}$ shows $T_{\mathrm{on} \_ \text {max }}-T_{\mathrm{on} \_ \text {min }}$ as a function of pressure under different rotation cycles. The pressure effect is clearly visible when the rotation cycle is $15 \mathrm{~s}$. Because the experiment is conducted at $T=25^{\circ} \mathrm{C}$ and $v=5 \mathrm{~m} \mathrm{~s}^{-1}$, the effect of rotation at the lowest considered temperature $\left(-67^{\circ} \mathrm{C}\right)$ is estimated using Eqs. (6), (7), and (8). At $P=5 \mathrm{hPa}$, the value of $T_{\text {on_max }}-T_{\text {on_min }}$ at $-67^{\circ} \mathrm{C}$ is $20 \%$ higher than that at $25^{\circ} \mathrm{C}$.

The maximum value of $T_{\text {on_max }}-T_{\text {on_min }}$ in the UAS $\left(0.05^{\circ} \mathrm{C}\right)$ is much smaller than that of von Rohden et al. (2022) $\left(0.3^{\circ} \mathrm{C}\right)$. In the work of von Rohden et al. (2022), although the distance from the light source to the sensor is constant, that to the sensor boom changes with rotation. This may be the reason why the maximum peak appears once in a 

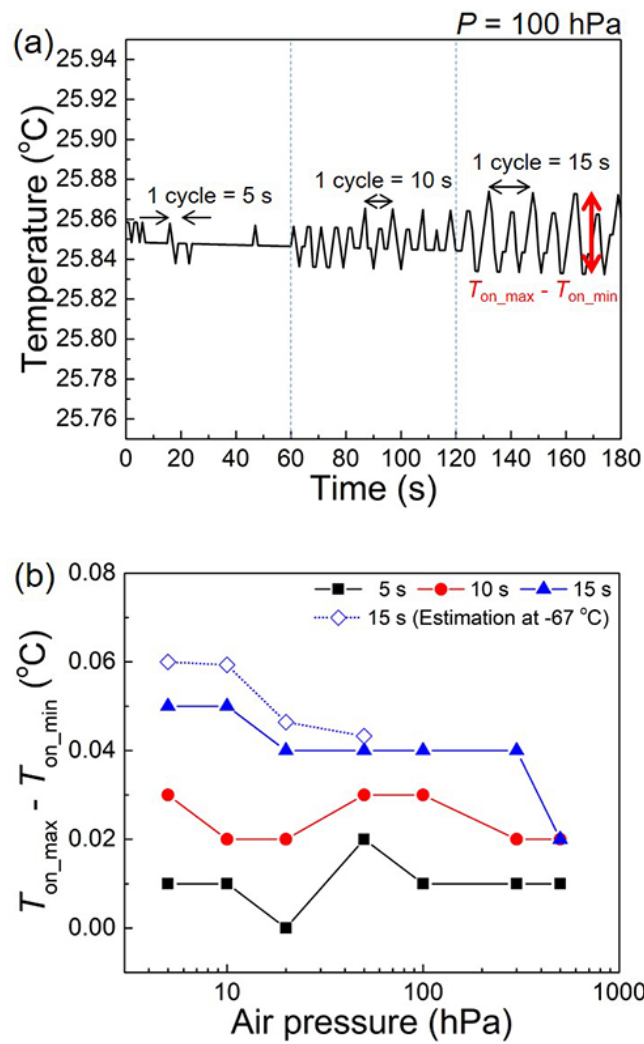

Figure 6. (a) Effect of sensor rotation with varied cycles (5, 10, and $15 \mathrm{~s}$ ) at $T=25^{\circ} \mathrm{C}$ and $v=5 \mathrm{~m} \mathrm{~s}^{-1}$ and (b) difference in the maximum and minimum temperature values $\left(T_{\mathrm{On} \_\max }-T_{\mathrm{On} \_\min }\right)$ as a function of the air pressure. $T_{\text {on_max }}-T_{\text {on } \_ \text {min }}$ at 100 and $5 \mathrm{hPa}$ at $-67^{\circ} \mathrm{C}$ is estimated using Eqs. (6), (7), and (8).

full cycle when the sensor boom is close to the light source, and the $T_{\text {on_max }}-T_{\text {on_min }}$ is bigger than this work. It should be highlighted that the relatively small $T_{\text {on_max }}-T_{\text {on_min }}$ with respect to $\Delta T_{\text {rad }}$ observed in this work suggests that the contribution of the thermal conduction to $\Delta T_{\text {rad }}$ is small compared to that by the direct irradiation of the sensor.

\subsection{Effect of solar incident angle}

The incident angle of irradiation to sensors primarily depends on the solar elevation angle and, during soundings, may also vary due to pendulum motion of the radiosonde. To investigate the effect of the solar incident angle, the sensor boom is tilted by $\theta$ with respect to the normal direction in the test chamber, as shown in Fig. 1e. Figure 7a shows $\Delta T_{\text {rad }}$ as a function of pressure when the sensor boom is in the normal and tilted $\left(\theta=27^{\circ}\right)$ positions. $\Delta T_{\text {rad }}$ in the tilted position (red circle) is lower than that in the normal position (black square) because the effective irradiance $\left(S_{\text {eff }}\right)$ is reduced by the tilting $\left(S_{\text {eff }}=S \times \cos 27^{\circ}\right)$. Because $\Delta T_{\text {rad }}$ is proportional to $S_{\text {eff }}$, the ratio $\Delta T_{\text {rad_tiled }} / \Delta T_{\text {rad_normal }}$ should be $\cos 27^{\circ}$. The ratio roughly follows the theoretical value (dotted blue line). However, this value is slightly higher and lower than $\cos 27^{\circ}$ at pressure values less and more than $50 \mathrm{hPa}$, respectively. At higher pressures, this deviation can be explained by the effect of ventilation, which intensifies in the case of tilting of the sensor boom. However, the reason for the deviation from the theoretical value at low pressures remains unclear. In this paper, the effect of solar incident angle (or tilt angle, $\theta)$ is considered by using $S_{\text {eff }}(S \times \cos \theta)$, and thus Eq. (10) is revised into its final form as follows:

$$
\begin{aligned}
\Delta T_{\text {rad }} & =\left(S_{\text {eff }} S_{0}^{-1}\right) \times\left[A_{0}(T)+B_{0}(T) \cdot \log (P)\right. \\
& \left.+C_{0}(T) \cdot[\log (P)]^{2}-0.027 \cdot(v-5)\right] \\
& \text { for } 5 \mathrm{hPa} \leq P \leq 500 \mathrm{hPa}, \quad S_{0}=980 \mathrm{~W} \mathrm{~m}^{-2} .
\end{aligned}
$$

Figure $7 \mathrm{~b}$ shows the difference between $\Delta T_{\text {rad_tilted }}$ and $\Delta T_{\text {rad_normal }} \times \cos 27^{\circ}$ as a function of the pressure. Because the experiment is conducted at $T=25^{\circ} \mathrm{C}$, the effect of the solar incident angle at the lowest considered temperature $\left(-67^{\circ} \mathrm{C}\right)$ is estimated using Eqs. (6), (7), and (8). At $P=5 \mathrm{hPa}, \Delta T_{\text {rad_tilted }}-\Delta T_{\text {rad_normal }} \times \cos 27^{\circ}$ at $-67^{\circ} \mathrm{C}$ is $20 \%$ higher than that at $25^{\circ} \mathrm{C}$. This value is used for the uncertainty due to the tilting of the sensor boom in Sect. 4.7.

\section{Uncertainty}

\subsection{Uncertainty factors}

The uncertainty factors that contribute to the uncertainty budget of the radiation correction are summarized in Table 4, in addition to the experimental ranges considered in this work.

\subsection{Uncertainty in the temperature, $u(T)$}

The temperature of the test chamber is measured using a PRT installed in a shaded area. The PRT is calibrated at KRISS, and the calibration uncertainty is $0.025^{\circ} \mathrm{C}$ with the coverage factor $k=1$. The resistance of the PRT is measured using a digital multimeter calibrated at KRISS. Moreover, the stability of the temperature measured using the PRT is considered in determining $u(T)$. The uncertainty components and their contributions to $u(T)$ are listed in Table 5.

\subsection{Uncertainty in the pressure, $u(P)$}

The pressure of the test chamber is measured using three pressure gauges for different pressure ranges. The gauges are calibrated at KRISS, and the calibration uncertainty is considered in determining $u(P)$. Moreover, the stability of the pressure measured using each pressure gauge is considered to determine $u(P)$. The uncertainty components and their contributions to $u(P)$ are listed in Table 6 . 
Table 4. Uncertainty factors and experimental ranges considered in this work.

\begin{tabular}{lrrrrl}
\hline Figure & $\begin{array}{r}T \\
\left({ }^{\circ} \mathrm{C}\right)\end{array}$ & $\begin{array}{r}P \\
(\mathrm{hPa})\end{array}$ & $\begin{array}{r}v \\
\left(\mathrm{~m} \mathrm{~s}^{-1}\right)\end{array}$ & $\begin{array}{r}S \\
\left(\mathrm{~W} \mathrm{~m}^{-2}\right)\end{array}$ & Position/motion \\
\hline 2 & -67 to 20 & $5-500$ & 5 & 980 & Normal \\
$4 \mathrm{a}$ & -67 to 20 & 50 & $4-7$ & 980 & Normal \\
$4 \mathrm{~b}$ & -40 & $5-300$ & $4-7$ & 980 & Normal \\
5 & 25 & $5-500$ & 5 & 980 & $360^{\circ}$ rotation \\
6 & 25 & $5-500$ & 5 & 980 & $27^{\circ}$ tilted \\
\hline
\end{tabular}

(a)
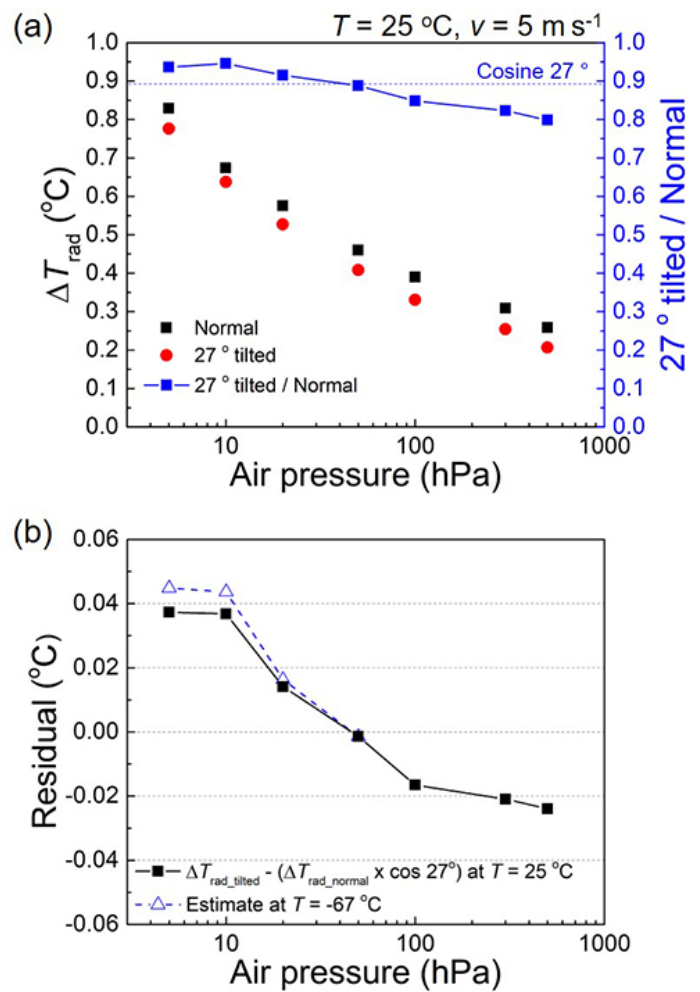

Figure 7. (a) Effect of tilting of the sensor boom showing (left $y$ axis) $T_{\text {rad }}$ with normal $\left(T_{\text {rad_normal }}\right)$ and $27^{\circ}$ tilted position ( $\left.T_{\text {rad_tilted }}\right)$ and the ratio between them (right $y$ axis). (b) Residual between $T_{\text {rad_tilted }}$ and $T_{\text {rad_normal }} \times \cos 27^{\circ}$ at $T=25^{\circ} \mathrm{C}$ and the estimate of the residual at $T=-67^{\circ} \mathrm{C}$ by using Eqs. (6), (7), and (8).

Table 5. Uncertainty budget for the test chamber temperature.

\begin{tabular}{lr}
\hline Uncertainty component & $\begin{array}{r}\text { Contribution } \\
\left({ }^{\circ} \mathrm{C}\right)\end{array}$ \\
\hline Calibration of the PRT & 0.025 \\
Calibration of the multimeter & 0.010 \\
Stability of temperature measurement & 0.007 \\
\hline$u(T), k=1$ & 0.028 \\
\hline
\end{tabular}

Atmos. Meas. Tech., 15, 1107-1121, 2022
Table 6. Uncertainty budget for the test chamber pressure.

\begin{tabular}{lrr}
\hline Uncertainty component & $\begin{array}{r}\text { Pressure range } \\
(\mathrm{hPa})\end{array}$ & $\begin{array}{r}\text { Contribution } \\
(\mathrm{hPa})\end{array}$ \\
\hline Calibration of the & $0-10$ & 0.007 \\
pressure gauge & $10-100$ & 0.08 \\
& $100-1000$ & 0.1 \\
\hline Stability of pressure & $0-10$ & 0.005 \\
measurement & $10-100$ & 0.11 \\
& $100-1000$ & 0.14 \\
\hline$u(P), k=1$ & $0-10$ & 0.01 \\
& $10-100$ & 0.14 \\
& $100-1000$ & 0.18 \\
\hline
\end{tabular}

\subsection{Uncertainty in the ventilation speed, $u(v)$}

The SI traceability of the ventilation speed in the test chamber of the UAS is ensured by calibrating the sonic nozzles at KRISS. The calibration uncertainty of the sonic nozzles is $0.09 \%(k=1)$. The stability of the ventilation speed in the test chamber is considered to determine $u(v)$. The spatial gradient of the ventilation speed in the test chamber is measured through the LDV at KRISS. The measurement dimension using the LDV was $30 \mathrm{~mm} \times 30 \mathrm{~mm}$ around the sensor (central) location with $5 \mathrm{~mm}$ intervals (49 points). Thus, the outermost measurement points were spaced $10 \mathrm{~mm}$ apart from the walls of the test chamber $(50 \mathrm{~mm} \times 50 \mathrm{~mm})$. The measurement was performed under the condition of $v=4.67 \mathrm{~m} \mathrm{~s}^{-1}$ (reference value), $P=550 \mathrm{hPa}$, and room temperature. The flow regime is turbulent because the Reynolds number is high $\left(\sim 10^{5}\right)$ under this experimental condition. The average and the standard deviation by the LDV over the entire measurement area were 4.63 and $0.47 \mathrm{~m} \mathrm{~s}^{-1}$, respectively. Although the flow rate of the outermost points tends to be smaller than others, no significant spatial gradient is observed. This may be because of the spacing $(10 \mathrm{~mm})$ between the outermost measurement points and the walls of the test chamber. The difference between the reference and the measurement average is assumed to have a rectangular probability distribution for the calculation of the uncertainty in the spatial gradient. Then, the standard uncertainty of this estimate is the half width of the distribution divided by $\sqrt{3}$ (ISO, 2008). The uncertainty com- 
Table 7. Uncertainty budget for the ventilation speed in the test chamber.

\begin{tabular}{lc}
\hline Uncertainty component & $\begin{array}{c}\text { Contribution } \\
\left(\mathrm{m} \mathrm{s}^{-1}\right)\end{array}$ \\
\hline Calibration of sonic nozzles & 0.005 \\
Stability & 0.052 \\
Spatial gradient & 0.026 \\
\hline$u(v), k=1$ & 0.058 \\
\hline
\end{tabular}

Table 8. Uncertainty budget for the irradiance in the test chamber.

\begin{tabular}{lr}
\hline Uncertainty component & $\begin{array}{r}\text { Contribution } \\
\left(\mathrm{W} \mathrm{m}^{-2}\right)\end{array}$ \\
\hline Calibration of pyranometer & 9.8 \\
Stability & 6.0 \\
Spatial gradient & 28.3 \\
\hline$u(S), k=1$ & 30.5 \\
\hline
\end{tabular}

ponents and their contributions to $u(v)$ are summarized in Table 7.

\subsection{Uncertainty in the irradiance, $u(S)$}

The irradiance in the test chamber is measured using a pyranometer. The pyranometer is calibrated at KRISS, and the calibration uncertainty is $9.8 \mathrm{~W} \mathrm{~m}^{-2}$ at $k=1$. The stability of the irradiance measured using the pyranometer is considered to determine $u(S)$. The uncertainty of the solar simulator will be negligible compared to that of the actual radiation field in atmospheric soundings due to the lack of knowledge. In addition, the two-dimensional spatial uniformity of the irradiance in the test chamber is measured by moving the pyranometer. The spatial gradient is within $\pm 5 \%$, and a rectangular probability distribution is assumed for the uncertainty calculation. The uncertainty components and their contributions to $u(S)$ are summarized in Table 8.

\subsection{Uncertainty due to sensor rotation}

Since the sensor boom position for $T_{\text {on_max }}$ during the rotation corresponds to the normal position, the uncertainty due to sensor rotation is obtained based on $T_{\text {on_max }}-T_{\text {on_min }}$, as shown in Fig. 6b. The value estimated for $T=-67^{\circ} \mathrm{C}$ and $P=5 \mathrm{hPa}$ is used to include sufficient uncertainty. The values are assumed to have a rectangular distribution, and thus, the corresponding standard uncertainty $(k=1)$ is obtained considering the half-maximum value $\left(0.03{ }^{\circ} \mathrm{C}\right)$ divided by $\sqrt{3}$. The reason for using the half maximum is that $T_{\text {on_max }}-$ $T_{\text {on_min }}$ is about double $T_{\text {on_max }}-T_{\text {on }}$ or $T_{\text {on }}-T_{\text {on_min }}$. Consequently, the uncertainty due to sensor rotation is $0.017^{\circ} \mathrm{C}$ $(k=1)$.

\subsection{Uncertainty due to tilting of the sensor}

The uncertainty due to tilting of the sensor boom is obtained using $T_{\text {on tilted }}-T_{\text {on normal }} \cdot \cos 27^{\circ}$, as shown in Fig. $7 \mathrm{~b}$. The value estimated for $T=-67^{\circ} \mathrm{C}$ and $P=5 \mathrm{hPa}$ is used to include sufficient uncertainty. The values are assumed to have a rectangular distribution, and thus, the corresponding standard uncertainty $(k=1)$ is obtained considering the maximum value $\left(0.045^{\circ} \mathrm{C}\right)$ divided by $\sqrt{3}$. Consequently, the uncertainty due to sensor rotation is $0.026^{\circ} \mathrm{C}(k=1)$.

\subsection{Uncertainty due to fitting error}

Because Eq. (11) is used for the final radiation correction, the residuals shown in Figs. $2 \mathrm{~b}$ and $5 \mathrm{c}$ must be considered in determining the uncertainty. The residuals are assumed to have a rectangular distribution, and thus, the corresponding standard uncertainty $(k=1)$ is obtained considering the maximum absolute value divided by $\sqrt{3}$. Consequently, the uncertainty due to the fitting error is $0.023^{\circ} \mathrm{C}(k=1)$.

\subsection{Uncertainty budget for radiation correction}

The uncertainties in $T, P, v$, and $S$ contribute to the uncertainty in the radiation correction by the uncertainty propagation law based on Eq. (11):

$$
\begin{aligned}
& \frac{\partial \Delta T_{\mathrm{rad}}}{\partial T} \cdot u(T), \\
& \frac{\partial \Delta T_{\mathrm{rad}}}{\partial P} \cdot u(P), \\
& \frac{\partial \Delta T_{\mathrm{rad}}}{\partial v} \cdot u(v), \\
& \frac{\partial \Delta T_{\mathrm{rad}}}{\partial S} \cdot u(S),
\end{aligned}
$$

where $u$ (parameter) represents the standard uncertainty in each parameter at $k=1$, and the partial differential terms represent the sensitivity coefficients. The sensitivity coefficients of the uncertainties due to sensor rotation, tilting of the sensor, and fitting error are 1 because they directly contribute to the uncertainty in the radiation correction. The uncertainty budget for the radiation correction $\left(\Delta T_{\mathrm{rad}}\right)$ based on the conducted experiments is presented in Table 9.

\subsection{Uncertainty budget for the corrected temperature, $T_{\text {cor }}$}

The corrected temperature $\left(T_{\text {cor }}\right)$ is obtained by subtracting $\Delta T_{\text {rad }}$ from the raw temperature $\left(T_{\text {raw }}\right)$ as follows:

$T_{\text {cor }}=T_{\text {raw }}-\Delta T_{\text {rad }}$

Thus, the uncertainty in the corrected temperature, $u\left(T_{\text {cor }}\right)$, is calculated as follows:

$u\left(T_{\text {cor }}\right)^{2}=u\left(T_{\text {raw }}\right)^{2}+u\left(\Delta T_{\text {rad }}\right)^{2}$, 
Table 9. Uncertainty budget of the radiation correction $\left(\Delta T_{\text {rad }}\right)$.

\begin{tabular}{lrlrc}
\hline $\begin{array}{l}\text { Uncertainty } \\
\text { factor }\end{array}$ & Condition & Unit & $\begin{array}{r}\text { Standard } \\
\text { uncertainty } \\
(k=1)\end{array}$ & $\begin{array}{r}\text { Contribution to } \\
\text { uncertainty in radiation } \\
\text { correction }(k=2)\end{array}$ \\
\hline$T$ & -67 & ${ }^{\circ} \mathrm{C}$ & 0.028 & $0.000^{\circ} \mathrm{C}$ \\
$P$ & 5 & $\mathrm{hPa}^{\circ}$ & 0.01 & $0.000{ }^{\circ} \mathrm{C}$ \\
$v$ & 5 & $\mathrm{~m} \mathrm{~s}^{-1}$ & 0.058 & $0.004^{\circ} \mathrm{C}$ \\
$S$ & 980 & $\mathrm{~W} \mathrm{~m}^{-2}$ & 30.5 & $0.062^{\circ} \mathrm{C}$ \\
Rotation & 24 & ${ }^{\circ} \mathrm{s}^{-1}$ & - & $0.035^{\circ} \mathrm{C}$ \\
Tilting & 27 & ${ }^{\circ}$ & - & $0.052^{\circ} \mathrm{C}$ \\
Fitting error & -0.024 to 0.04 & ${ }^{\circ} \mathrm{C}$ & 0.023 & $0.046^{\circ} \mathrm{C}$ \\
\hline Expanded uncertainty in radiation correction $(k=2)$ & $0.100^{\circ} \mathrm{C}$ \\
\hline
\end{tabular}

where $u\left(T_{\text {raw }}\right)$ is the standard uncertainty in the raw temperature $(k=1)$. The uncertainty in $\Delta T_{\text {rad }}$, indicated in Table 9 , must be rescaled in proportion to the actual solar irradiance for Eq. (17). Therefore, the uncertainty in $\Delta T_{\text {rad }}$ is scaled up to a level of solar constant $\left(\sim 1360 \mathrm{~W} \mathrm{~m}^{-2}\right)$ by a factor of $1360 / 980$ based on the linear relationship between $\Delta T_{\mathrm{rad}}$ and $S$.

The calibration uncertainty associated with the temperature sensor must be considered to account for the uncertainty in the raw temperature, $u\left(T_{\text {raw }}\right)$. Consequently, the expanded uncertainty in the corrected temperature of the RS41 is $0.138{ }^{\circ} \mathrm{C}(k=2)$, as indicated in Table 10 . The calibration uncertainty in the RS41 temperature sensor, $U\left(T_{\text {raw }}\right)$ $(k=2)$, is specified by the manufacturer (Vaisala, 2022). Since Vaisala provides additional uncertainty in reproducibility in sounding $\left(0.15^{\circ} \mathrm{C}\right.$ when $P>100 \mathrm{hPa}, 0.3^{\circ} \mathrm{C}$ when $P<100 \mathrm{hPa}$ ) (Vaisala, 2022), this should be added to the total uncertainty in the corrected temperature when the radiation correction formula in Eq. (11) is applied to soundings.

\subsection{Comparison of RS41 radiation correction specified by Vaisala and that obtained through the UAS}

The radiation correction of the RS41 by the UAS is based on Eq. (11) for different pressure ranges. In order to apply the correction formula to actual soundings, the effective irradiance to the sensor should be known. However, radiosondes constantly change positions with respect to the solar irradiation through rotation and pendulum motion; the calculation of effective irradiance resorts to the mean of effective irradiance over the motion of radiosondes. Figure 8 a shows a schematic diagram of a radiosonde with parameters that affect the effective irradiance $S_{\text {eff }}$ on the sensor. Then, the effective irradiance to the sensor can be calculated as follows:

$S_{\mathrm{eff}}=S_{\mathrm{dir}} \cdot|\cos \alpha \cos \theta \cos \varphi-\sin \theta \sin \alpha|$.

$S_{\text {dir }}$ is solar direct irradiance, $\theta$ is boom tilting angle, $\alpha$ is solar elevation angle, and $\varphi$ is azimuthal angle. The effective irradiation area $\left(A_{\text {eff }} / A_{0}\right)$ on the sensor boom is averaged over rotation $(\varphi)$ with a fixed tilting angle $\theta=45^{\circ}$ and plotted as a function of the solar elevation angle as shown in Fig. 8b. Using this effective irradiance, the radiation correction by the UAS is obtained and compared with that of the manufacturer at two different $\alpha$ values ( 45 and $90^{\circ}$ ), as shown in Fig. 9. For the UAS correction, the solar direct irradiance is assumed to be $1360 \mathrm{~W} \mathrm{~m}^{-2}$ at all pressure values. To simulate the albedo effect, the radiation correction with additional irradiance of $400 \mathrm{~W} \mathrm{~m}^{-2}$ is also calculated. Consequently, the radiation correction of the UAS is smaller than the Vaisala by about $0.5-0.7^{\circ} \mathrm{C}$ at $-70^{\circ} \mathrm{C}$ and $5 \mathrm{hPa}$ when only the solar direct irradiance $\left(1360 \mathrm{~W} \mathrm{~m}^{-2}\right)$ is considered with the solar elevation angle $\alpha=45-90^{\circ}$. When the albedo effect is additionally included $\left(400 \mathrm{~W} \mathrm{~m}^{-2}\right)$, the gap between the two corrections is reduced to $0.04-0.4^{\circ} \mathrm{C}$ at $-70{ }^{\circ} \mathrm{C}$ and $5 \mathrm{hPa}$ with $\alpha=45-90^{\circ}$. Since solar direct irradiance $\left(1360 \mathrm{~W} \mathrm{~m}^{-2}\right)$ and additional diffuse irradiance $\left(400 \mathrm{~W} \mathrm{~m}^{-2}\right)$ are applied for all pressures, the radiation correction of this work can be exaggerated at high pressures. The radiation correction of the UAS is smaller than that of the manufacturer at low pressures, which is consistent with the recent finding using an independent laboratory set-up. In the work of von Rohden et al. (2022), the radiation correction was smaller than the manufacturer's by $0.35 \mathrm{~K}$ at $35 \mathrm{~km}$. The radiation corrections of the manufacturer and the UAS at some representative conditions are summarized in Table 11.

\section{Conclusions}

The UAS developed at KRISS provides a unique opportunity to correct the solar radiation effect on commercial radiosondes by reproducing the environments that may be encountered by radiosondes by simultaneously controlling $T, P, v$, and $S$. The following ranges of $T, P$, and $v$ are considered in this study: -67 to $20^{\circ} \mathrm{C}, 5-500 \mathrm{hPa}$, and $4-7 \mathrm{~m} \mathrm{~s}^{-1}$, respectively, with a fixed $S_{0}=980 \mathrm{~W} \mathrm{~m}^{-2}$. The functionalities of rotating and tilting the sensor boom are added considering the previous report on the UAS (Lee et al., 2020) to investigate the effect of the radiosonde motions with respect to the 
Table 10. Uncertainty budget for the corrected temperature.

\begin{tabular}{lc}
\hline Uncertainty factor & Uncertainty $(k=2)$ \\
\hline Expanded uncertainty for the radiation correction at $1360 \mathrm{~W} \mathrm{~m}^{-2}, U\left(\Delta T_{\text {rad }}\right)$ & $0.138^{\circ} \mathrm{C}$ \\
Calibration of the RS41 temperature sensor (Vaisala, 2022), $U\left(T_{\text {raw }}\right)$ & $0.100^{\circ} \mathrm{C}$ \\
\hline Expanded uncertainty in the corrected temperature, $U\left(T_{\text {cor }}\right)$ & $0.170^{\circ} \mathrm{C}$ \\
\hline
\end{tabular}

Table 11. Radiation correction of the RS41 by the manufacturer (Vaisala, 2022) and the UAS using Eq. (11).

\begin{tabular}{|c|c|c|c|c|c|c|c|}
\hline \multirow[b]{2}{*}{$\begin{array}{l}\text { Pressure } \\
(\mathrm{hPa})\end{array}$} & \multicolumn{3}{|c|}{$\begin{array}{l}\text { Radiation correction by Vaisala } \\
\qquad\left(v=6 \mathrm{~m} \mathrm{~s}^{-1}\right)\end{array}$} & \multicolumn{4}{|c|}{$\begin{array}{c}\text { Radiation correction by the UAS } \\
\left(v=6 \mathrm{~m} \mathrm{~s}^{-1}, S_{\mathrm{dir}}=1360 \mathrm{~W} \mathrm{~m}^{-2}, \theta=45^{\circ}\right)\end{array}$} \\
\hline & $\alpha=0^{\circ}$ & $\alpha=45^{\circ}$ & $\alpha=90^{\circ}$ & $\begin{array}{c}T=-70^{\circ} \mathrm{C} \\
\alpha=0^{\circ}\end{array}$ & $\begin{array}{l}T=-70^{\circ} \mathrm{C} \\
\alpha=45^{\circ}\end{array}$ & $\begin{array}{c}T=-70^{\circ} \mathrm{C} \\
\alpha=90^{\circ}\end{array}$ & $\begin{array}{c}T=-70^{\circ} \mathrm{C}, \\
\alpha=90^{\circ}, \\
+400 \mathrm{~W} \mathrm{~m}^{-2}\end{array}$ \\
\hline 1000 & $0.00^{\circ} \mathrm{C}$ & $0.10^{\circ} \mathrm{C}$ & $0.11^{\circ} \mathrm{C}$ & $0.15^{\circ} \mathrm{C}$ & $0.17^{\circ} \mathrm{C}$ & $0.24^{\circ} \mathrm{C}$ & $0.33^{\circ} \mathrm{C}$ \\
\hline 500 & $0.03{ }^{\circ} \mathrm{C}$ & $0.17^{\circ} \mathrm{C}$ & $0.19^{\circ} \mathrm{C}$ & $0.17^{\circ} \mathrm{C}$ & $0.19^{\circ} \mathrm{C}$ & $0.26^{\circ} \mathrm{C}$ & $0.37^{\circ} \mathrm{C}$ \\
\hline 200 & $0.09^{\circ} \mathrm{C}$ & $0.29^{\circ} \mathrm{C}$ & $0.32^{\circ} \mathrm{C}$ & $0.21^{\circ} \mathrm{C}$ & $0.23^{\circ} \mathrm{C}$ & $0.33^{\circ} \mathrm{C}$ & $0.47^{\circ} \mathrm{C}$ \\
\hline 100 & $0.16^{\circ} \mathrm{C}$ & $0.42^{\circ} \mathrm{C}$ & $0.45^{\circ} \mathrm{C}$ & $0.26^{\circ} \mathrm{C}$ & $0.29^{\circ} \mathrm{C}$ & $0.41^{\circ} \mathrm{C}$ & $0.58^{\circ} \mathrm{C}$ \\
\hline 50 & $0.24{ }^{\circ} \mathrm{C}$ & $0.58^{\circ} \mathrm{C}$ & $0.62{ }^{\circ} \mathrm{C}$ & $0.32{ }^{\circ} \mathrm{C}$ & $0.36^{\circ} \mathrm{C}$ & $0.51^{\circ} \mathrm{C}$ & $0.72{ }^{\circ} \mathrm{C}$ \\
\hline 20 & $0.39^{\circ} \mathrm{C}$ & $0.85^{\circ} \mathrm{C}$ & $0.90^{\circ} \mathrm{C}$ & $0.43^{\circ} \mathrm{C}$ & $0.48^{\circ} \mathrm{C}$ & $0.67^{\circ} \mathrm{C}$ & $0.95^{\circ} \mathrm{C}$ \\
\hline 10 & $0.53^{\circ} \mathrm{C}$ & $1.10^{\circ} \mathrm{C}$ & $1.16^{\circ} \mathrm{C}$ & $0.53^{\circ} \mathrm{C}$ & $0.58^{\circ} \mathrm{C}$ & $0.82^{\circ} \mathrm{C}$ & $1.16^{\circ} \mathrm{C}$ \\
\hline 5 & $0.68^{\circ} \mathrm{C}$ & $1.39^{\circ} \mathrm{C}$ & $1.45^{\circ} \mathrm{C}$ & $0.64^{\circ} \mathrm{C}$ & $0.71^{\circ} \mathrm{C}$ & $1.00^{\circ} \mathrm{C}$ & $1.41^{\circ} \mathrm{C}$ \\
\hline
\end{tabular}

(a)
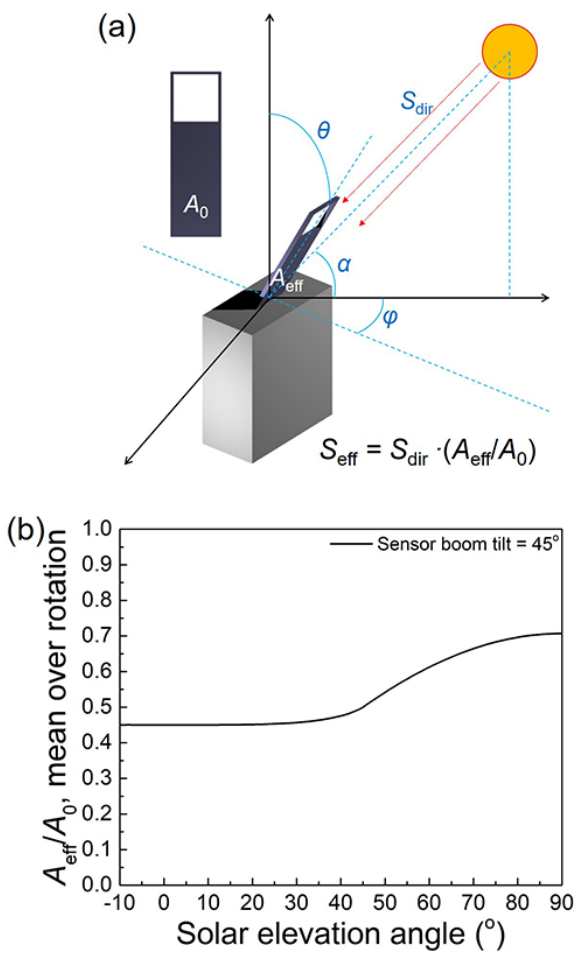

Figure 8. (a) Schematic diagram for the calculation of effective solar irradiance to the sensor. $\theta, \alpha$, and $\varphi$ are the tilting angle of the sensor boom, solar elevation angle, and azimuthal angle, respectively. (b) Effective irradiation area of the sensor boom obtained by the mean over the rotating radiosonde $(\varphi)$ as a function of solar elevation angle $(\alpha)$ with the tilting angle $\theta=45^{\circ}$. solar irradiation direction during ascent. The correction formula for the radiation effect on a Vaisala RS41 temperature sensor is derived through a series of experiments with varying environmental parameters as well as motions and positions of the radiosonde sensor. In addition, an empirical formula is derived to estimate the low-temperature effect by using only the inputs of room-temperature measurements.

The uncertainty associated with the radiation correction is evaluated by combining the contribution of each uncertainty factor. The uncertain factors considered for the radiation correction are $T, P, v$, and $S$ as well as the sensor rotation, sensor tilting, and data-fitting-induced errors. The uncertainty budget for the radiation correction of the RS41 temperature sensor is $0.1^{\circ} \mathrm{C}$ at $k=2$. When the uncertainty in the absolute temperature measurement (calibration uncertainty) is included, the uncertainty in the corrected temperature is estimated to be $0.17^{\circ} \mathrm{C}$ at $k=2$. The radiation correction values by the UAS are provided when the solar constant $\left(1360 \mathrm{~W} \mathrm{~m}^{-2}\right)$ is used for $S$ for the comparison with those by the manufacturer. The radiation correction by the UAS depends on effective solar irradiance. Thus, the measurement of solar irradiance in situ and the calculation of effective irradiance are desirable to reflect the conditions such as clouding, solar elevation angle, and radiosonde movement, thereby obtaining more accurate correction values. To measure the solar irradiance in situ, a radiosonde model using dual temperature sensors with different emissivity values has already been tested using the UAS. The temperature difference in the two sensors of the radiosonde is recorded with varying 
(a)
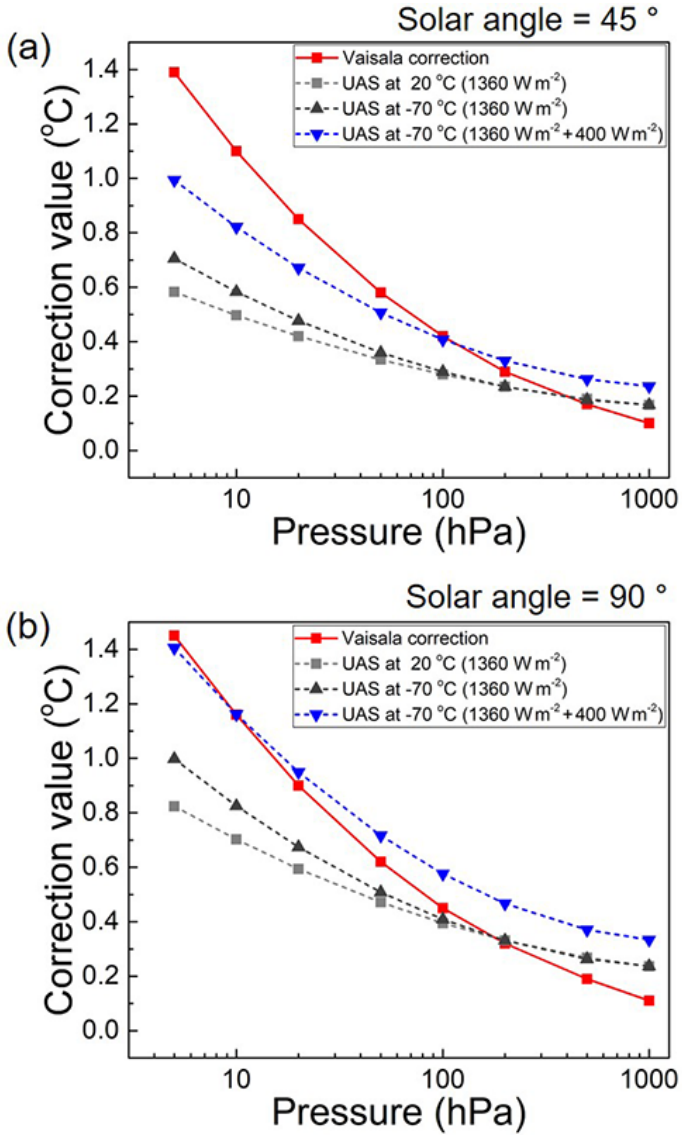

Figure 9. Comparison of the radiation correction value between the Vaisala and the UAS as a function of pressure when the solar elevation angle is (a) $\alpha=45^{\circ}$ and (b) $\alpha=90^{\circ}$ with a boom tilting angle of $\theta=45^{\circ}$

environmental parameters in the UAS to be reversely used to measure solar irradiance in situ during sounding. In this sense, the approach based on dual sensors is different from previous works that estimate the air temperature using several other temperatures measured by sensors with different emissivity (Schmidlin et al., 1986).

As the UAS can support wired and wireless data acquisition, it can be used for any type of commercial radiosonde to derive the radiation correction along with the corresponding uncertainty. Therefore, the UAS can help enhance the measurement accuracy of commercial radiosondes within the framework of the SI traceability.

Code availability. The operation programme of the upper-air simulator based on LabVIEW software is available upon request.

Data availability. The laboratory experiment data used for Figs. 1 to 9 are available upon request.
Author contributions. SWL analysed the experimental data and wrote the manuscript. SKi and YSL conducted experiments. BIC built the humidity control system, WK and YKO built the airflow control system, and SP and JKY established the solar simulator setup. JL conducted theoretical calculation. SL and SKw developed the measurement software. YGK designed the experiments.

Competing interests. The contact author has declared that neither they nor their co-authors have any competing interests.

Disclaimer. Publisher's note: Copernicus Publications remains neutral with regard to jurisdictional claims in published maps and institutional affiliations.

Financial support. This research has been supported by the Korea Research Institute of Standards and Science (grant no. GP20210005-02).

Review statement. This paper was edited by Roeland Van Malderen and reviewed by Ruud Dirksen and one anonymous referee.

\section{References}

Choi, H. M., Park, K.-A., Oh, Y. K., and Choi, Y. M.: Uncertainty evaluation procedure and intercomparison of bell provers as a calibration system for gas flow meters, Flow Meas. Instrum., 21, 488-496, https://doi.org/10.1016/j.flowmeasinst.2010.07.002, 2010.

de Podesta, M., Bell, S., and Underwood, R.: Air temperature sensors: dependence of radiative errors on sensor diameter in precision metrology and meteorology, Metrologia, 55, 229, https://doi.org/10.1088/1681-7575/aaaa52, 2018.

Dirksen, R. J., Sommer, M., Immler, F. J., Hurst, D. F., Kivi, R., and Vömel, H.: Reference quality upper-air measurements: GRUAN data processing for the Vaisala RS92 radiosonde, Atmos. Meas. Tech., 7, 4463-4490, https://doi.org/10.5194/amt-7-4463-2014, 2014.

GCOS: GCOS Reference Upper-Air Network (GRUAN): Justification, requirements, siting and instrumentation options, GCOS, https://library.wmo.int/doc_num.php?explnum_id=3821 (last access: 5 August 2021), 2007.

Incropera, F. and DeWitt, D.: Introduction to heat transfer, 4th edition, John Wiley \& Sons, Inc., ISBN 100471386499 , ISBN 13 978-0471386490, 2002.

ISO: Measurement of Gas Flow by Means of Critical Flow Venturi Nozzles, ISO, https://www.iso.org/obp/ui/\#iso:std:iso:9300: ed-2:v1:en (last access: 2 March 2022), 2005.

ISO: Uncertainty of measurement - Part 3: Guide to the expression of uncertainty in measurement (GUM: 1995), ISO, https://www. iso.org/standard/50461.html (last access: 2 March 2022), 2008.

Lee, S. W., Choi, B. I., Kim, J. C., Woo, S. B., Park, S., Yang, S. G., and Kim, Y. G.: Importance of air pressure in the compensation for the solar radiation effect on tempera- 
ture sensors of radiosondes, Meteorol. Appl., 23, 691-697, https://doi.org/10.1002/met.1592, 2016.

Lee, S. W., Park, E. U., Choi, B. I., Kim, J. C., Woo, S. B., Park, S., Yang, S. G., and Kim, Y. G.: Correction of solar irradiation effects on air temperature measurement using a dual-thermistor radiosonde at low temperature and low pressure, Meteorol. Appl., 25, 283-291, https://doi.org/10.1002/met.1690, 2018a.

Lee, S. W., Park, E. U., Choi, B. I., Kim, J. C., Woo, S. B., Park, S., Yang, S. G., and Kim, Y. G.: Dual temperature sensors with different emissivities in radiosondes for the compensation of solar irradiation effects with varying air pressure, Meteorol. Appl., 25, 49-55, https://doi.org/10.1002/met.1668, 2018b.

Lee, S. W., Park, E. U., Choi, B. I., Kim, J. C., Woo, S. B., Kang, W., Park, S., Yang, S. G., and Kim, Y. G.: Compensation of solar radiation and ventilation effects on the temperature measurement of radiosondes using dual thermistors, Meteorol. Appl., 25, 209216, https://doi.org/10.1002/met.1683, 2018c.

Lee, S. W., Yang, I., Choi, B. I., Kim, S., Woo, S. B., Kang, W., Oh, Y. K., Park, S., Yoo, J. K., and Kim, J. C.: Development of upper air simulator for the calibration of solar radiation effects on radiosonde temperature sensors, Meteorol. Appl., 27, e1855, https://doi.org/10.1002/met.1855, 2020.

Lee, S. W., Kim, S., Choi, B. I., Woo, S. B., Lee, S., Kwon, S., and Kim, Y. G.: Calibration of RS41 humidity sensors by using an upper-air simulator, Meteorol. Appl., 28, e2010, https://doi.org/10.1002/met.2010, 2021.

Linstrom, P. J. and Mallard, W. G.: The NIST Chemistry WebBook: A chemical data resource on the internet, J. Chem. Eng. Data, 46, 1059-1063, https://doi.org/10.1021/je000236i, 2001.

Luers, J. K.: Estimating the temperature error of the radiosonde rod thermistor under different environments, J. Atmos. Ocean. Tech., 7, 882-895, https://doi.org/10.1175/15200426(1990)007<0882:ETTEOT>2.0.CO;2, 1990.
Luers, J. K. and Eskridge, R. E.: Temperature corrections for the VIZ and Vaisala radiosondes, J. Appl. Meteorol. Clim., 34, 1241-1253, https://doi.org/10.1175/15200450(1995)034<1241:TCFTVA>2.0.CO;2, 1995.

McMillin, L., Uddstrom, M., and Coletti, A.: A procedure for correcting radiosonde reports for radiation errors, J. Atmos. Ocean. Tech., 9, 801-811, https://doi.org/10.1175/15200426(1992)009<0801:APFCRR>2.0.CO;2, 1992.

Nash, J., Oakley, T., Vömel, H., and Li, W.: WMO intercomparisons of high quality radiosonde systems, WMO/TD-1580, WMO World Meteorological Organization, https://library.wmo.int/doc num.php?explnum_id=9467 (last access: 2 March 2022), 2011.

Philipona, R., Kräuchi, A., Romanens, G., Levrat, G., Ruppert, P., Brocard, E., Jeannet, P., Ruffieux, D., and Calpini, B.: Solar and thermal radiation errors on upper-air radiosonde temperature measurements, J. Atmos. Ocean. Tech., 30, 2382-2393, https://doi.org/10.1175/JTECH-D-13-00047.1, 2013.

Schmidlin, F. J., Luers, J. K., and Huffman, P.: Preliminary estimates of radiosonde thermistor errors, NASA - National Aeronautics and Space Administration of USA, https://ntrs.nasa. gov/api/citations/19870002653/downloads/19870002653.pdf (last access: 6 August 2021), 1986.

Vaisala: Vaisala Radiosonde RS41 Measurement Performance, https://www.vaisala.com/sites/default/files/documents/ WhitepaperRS41PerformanceB211356EN-A.pdf, last access: 2 March 2022.

von Rohden, C., Sommer, M., Naebert, T., Motuz, V., and Dirksen, R. J.: Laboratory characterisation of the radiation temperature error of radiosondes and its application to the GRUAN data processing for the Vaisala RS41, Atmos. Meas. Tech., 15, 383-405, https://doi.org/10.5194/amt-15-383-2022, 2022. 